\title{
Modeling salient nursing care to bridge classroom to clinical
}

\author{
Janet Lusk Monagle ${ }^{1}$, Karen Quinn Doherty ${ }^{2}$ \\ Lawrence Memorial/Regis College Nursing Program, Medford, USA.
}

Correspondence: Janet Lusk Monagle. Address: Lawrence Memorial/Regis College Nursing Program, 170 Governors Avenue, Medford, USA. Email: JMonagle@Imh.edu

Received: March 27, 2014

Accepted: June 3, 2014

Online Published: J une 17, 2014

DOI : 10.5430/jnep.v4n8p173

URL: http://dx.doi.org/10.5430/jnep.v4n8p173

\begin{abstract}
It is not possible to expose nursing students to all aspects of nursing practice while in school; educators must be creative to bridge the gap between classroom teaching and clinical practice. This qualitative study uses faculty made videos that model salient nursing care for students in the classroom setting followed by a structured debriefing session. The aim of the study is to analyze nursing student's perceptions of this method of teaching. Bandura's Social Learning Theory guides the study. Three themes emerge from viewing the videos and debriefing: the videos reinforce the learning; visual learning is valuable, and debriefing after the video is essential. Additionally, students enthusiastically support the method to enhance their learning.
\end{abstract}

\section{Key words}

Focus groups, Nursing students, Learning, Teaching strategy

\section{I ntroduction}

Nurse educators are faced with the challenge of preparing future nurses to care for patients with a variety of clinical situations. Due to limited ability to plan those clinical experiences, educators must have methods that teach aspects of nursing care that may never be practiced or modeled. The purpose of this qualitative research was to analyze nursing student's perceptions of the effect of modeling salient nursing care using faculty made videos in combination with a debriefing after the video. Video recordings of exemplary nursing care were used as supplemental strategy in the classroom. The teaching strategy was influenced by Bandura's observational learning theory of modeling components imbedded within Social Learning Theory. It was hypothesized that modeling specific salient aspects of nursing care followed by a structured debriefing would promote the perception of theory-clinical correlation and enhance learning. Findings validate that the video-debriefing combination is a valuable teaching strategy. Three themes emerge from viewing the videos and debriefing: the videos reinforce the learning; visual learning is valuable, and debriefing after the video is essential. Overall, students strongly support this method of teaching.

\section{Literature review}

The use of modeling as a teaching strategy dates back to Bandura's work in the early 1960's. The central principle of Bandura's theory is the social context of learning: Individuals gain knowledge from interaction with their environ- 
ment ${ }^{[1]}$. In addition, Bandura ${ }^{[1]}$ asserts the environment is inclusive of observing and modeling other individuals' attitudes and behaviors and cognition and one's self-efficacy belief is critical to one's ability and willingness to learn and to change. Thus, in 1986, Bandura ${ }^{[2]}$ renamed his theory Social Cognitive Theory (SCT). Bandura extended SCT to Self-Efficacy Theory. One's belief that a task can be performed is elemental to the success and accurate performance $\left.{ }^{[2]}\right)$. If one has a high degree of self-efficacy, this will correlate with a high degree of success ${ }^{[2-4]}$. Beginning nursing students often lack confidence and have difficulty imagining they can perform certain tasks or interact competently with patients. Therefore, the student's self-efficacy belief may be low and interfere with their competency. Zimmerman ${ }^{[5]}$ posits both individual self-efficacy and collective efficacy can be enhanced by observational learning, specifically modeling. Modeling is powerful in its ability to enhance learning at many levels ${ }^{[6]}$ ). Bandura ${ }^{[2]}$ promotes observational learning and believes information can be transmitted to many learners by just one model. Therefore, more than one student can benefit from viewing a video of well modeled nursing care.

Nursing authors agree that modeling has been part of nursing education because of its practice roots ${ }^{[7,8]}$. Modeling nursing behaviors is based on the idea that experienced nurses can share their knowledge in the context of a clinical situation and include the tacit knowledge that could be missed in the classroom setting ${ }^{[8]}$. Bahn ${ }^{[7]}$ applies Bandura's theory to nursing education, emphasizing the need for modeling in the clinical arena. However, the traditional clinical education model used in nursing education may have negative consequences ${ }^{[7]}$. Some practitioners may not exemplify appropriate nursing behaviors to students. As a consequence, faculty members are forced to describe correct nursing care that is in conflict with care practiced at a clinical site. Such inconsistencies may not be tolerated as well by impressionable beginning students, new to clinical practice ${ }^{[7]}$. More experienced students are better able to tolerate the ambiguity or ask for clarification from faculty. In a controlled environment with a specific modeling plan, the issue of poor modeling is eradicated but the tacit knowledge with appropriate context can be included. Thus, modeling appropriate skills and attitudes can be incorporated into videos.

\section{Method}

\subsection{Aim of the study}

The aim of this study was to gain an understanding of student perceptions of faculty made videos followed by a structured debriefing through the use of focus groups.

\subsection{Design}

An exploratory qualitative design with 5 focus groups was held in April-May 2013.

\subsection{Faculty made video strategy}

Faculty videos of nursing care scenarios feature care that may not be experienced while in nursing school, yet, are considered valuable to understand. Faculty in the Adult Nursing Practice Course brainstormed while considering their content area and identified seven focus areas. The objective was to choose salient nursing care scenarios that would likely not be modeled in the clinical area. Table 1 shows the faculty videos with anticipated student learning outcomes. Through the use of videos, the classroom was transformed; offering contextual learning and incorporating a model to promote the development of self-efficacy.

In addition to watching the videos, a debriefing template was used after all videos to structure the discussion. A structured, consistent approach enhances student learning and promotes clinical judgment development ${ }^{[9-11]}$. In addition, nursing authors agree that the use of debriefing exercises following simulation provides the best opportunity to synthesize learning ${ }^{[9,12-15]}$. Thus, debriefing following videos can be used to attain the same result. 
Table 1. Exemplar videos

\begin{tabular}{ll}
\hline Video Exemplar & Outcome \\
\hline End of Life Care & $\begin{array}{l}\text { Recognizes communication between nurse, patient, and family regarding } \\
\text { end-of-life } \\
\text { Identifies nursing interventions of assessing nasal drainage, recognizing signs of } \\
\text { increased intracranial pressure and intervening appropriately } \\
\text { pituitary hypophysectomy }\end{array}$ \\
$\begin{array}{ll}\text { Identifies that the patient is displaying symptoms of DKA, obtain vital signs and } \\
\text { a finger-stick, report all abnormal assessments and lab values to the physician }\end{array}$ \\
$\begin{array}{ll}\text { Acid-Base Balance: Management of a patient } \\
\text { with end stage COPD with an acute pneumonia }\end{array}$ & $\begin{array}{l}\text { Recognizes the patient in acute respiratory acidosis and intervenes appropriately } \\
\text { Interacting with a blind person }\end{array}$ \\
$\begin{array}{l}\text { Demonstrates approaching a blind person, how to ambulate and move within } \\
\text { unfamiliar environment }\end{array}$ \\
$\begin{array}{l}\text { tested positive for HIV (first test) } \\
\text { Stroke: Management of a patient S/P right sided } \\
\text { stroke with expressive (Broca's ) aphasia }\end{array}$ & $\begin{array}{l}\text { Uses communication techniques such as picture board. Demonstrates patience as } \\
\text { patient struggles to say a word without trying to fill in the blanks. }\end{array}$ \\
\hline
\end{tabular}

Arafeh, Hansen, and Nichols ${ }^{[16]}$ emphasize a debriefing structure which uses reflective questions specific to the situation and include a review of cognitive, technical, and behavioral objectives. The template includes small group discussion in the following areas: assessment factors; communication; priorities of care; leadership; and mood or feelings associated with the situation ${ }^{[17]}$. Every faculty made film integrates elements for discussion in each of the five areas noted, providing guidance for the debriefing. After showing the videos during one semester, a qualitative research study was planned to evaluate the strategy.

\subsection{Participants}

A convenience sample was obtained by inviting nursing students at a two year day and evening private nursing program located in the Northeast. Inclusion criteria: those who had viewed at least two of the faculty made videos in class and those who were taking their second nursing course. A total of 11 students from the day group (response rate 33\%) and 16 from the evening weekend group (response rate 52\%) participated in one of five focus groups. The sample included 25 woman and two men, ages 25-43.

\subsection{Data collection}

The primary author moderated the focus groups. A common interview guide was used to shape each group discussion (see Table 1). Focus groups lasted 15-25 minutes. Each focus group was audiotaped and then transcribed. At the end of each focus group the ideas were summarized and reported to group to ascertain correct perception of conversation. Each group of students stated that the summary was accurate and reflected their thoughts during the focus group (see Table 2).

Table 2. Focus Group Key Questions

- $\quad$ Did the videos help you understand the material?

- $\quad$ Did the videos impact your learning of the material?

- $\quad$ Did the discussions after the videos assist you in any way?

\subsection{Ethical considerations}

Institutional review Board (IRB) approval was obtained. The researcher recruited all participants and obtained written consent. There were no known risks to the study participants. All students were advised that their participation was totally voluntary. Since students are considered a vulnerable population, clinical course faculty were not involved in the 
recruiting process. To further minimize vulnerability, study participants were assured that their performance would have no effect on their grade ${ }^{[18]}$.

\section{Results}

\section{Data analysis}

Transcripts were analyzed following the seven steps of Colaizzi ${ }^{[19]}$. This method was deemed appropriate to extrapolate the student's feelings and identify themes from the data. The steps are described: After transcribing comments from the focus groups, all comments were read by two researchers. A list of comments was created and meanings were formulated for each. The meanings were clustered into three themes that the researchers agreed described a particular phenomenon. Together the researchers identified the phenomenon. Students were asked to validate if the themes accurately depicted their perception of the videos and debriefing ${ }^{[19]}$.

The first theme was that the videos reinforced the learning. The students stated that "it helped it click", it "drove the point home" and it "helped connect the dots." Students said there were able to "correlate the lecture (power point presentations) from class with the scenarios in the video." The groups also stated that during exams they would recall the video and it would help answer a related question. One student stated "seeing people you know helps make a better connection." This theme of reinforcing the learning of the content was mentioned by multiple students in all of the focus groups. Viewing video recordings of situations helps students prepare for practice by presenting predictable reactions. A person may perceive more control in a given situation because the modeling provided a strategy to cope with the situation ${ }^{[2]}$. In addition, having the videos available, enable faculty to show them whenever they want to continue to reinforce the learning.

The second theme was visual learning is valuable. Students stated that they were visual learners and they remembered the content better because they could see it in action. They felt that when they saw it the understood the concept better, it "brings it to life." Other comments: "watching it helps you remember better." One student said "it helps me to be more comfortable in a real situation." The visual learning theme enables the students to visualize the communication, observing the actual interaction: "I can picture in my head what to do and say." Seeing the interaction enhanced their ability to create mental representations to use later if needed.

The need to address different learning styles is imperative due to the diversity of the student population. Bandura ${ }^{[2]}$ believes that the structure of the social system in which the behavior is being modeled will also impact the likelihood of the attention that is paid to the modeling. Bandura ${ }^{[1]}$ discusses the advent of television as being an important mechanism to keeping attention to a modeled behavior as well as a way to transcend from ones immediate social environment to a different way to observe a behavior from another society. In today's world of advanced technology, educators are faced with multiple methods that students have available to observe behavior. The use of handheld devices in the clinical setting, portable computers, simulation, and social media all provide new ways for students to observe behaviors. The video exemplars are an example of this structure that will allow for enhanced learning for the visual learner.

The third theme reinforces debriefing after the video is essential. One student stated "talking right after makes it stick better, it was very beneficial." Another student discussed in the debriefing that "it was helpful seeing someone do it and then have a discussion about it." Important to the outcome of learning; one student commented that "discussing the video immediately afterward made me understand why the nurse was doing what she was doing." One student commented that explaining the priorities during the debriefing was very important to learning.

In nursing education, one knows that debriefing offers the opportunity for educators to elicit responses that clarify and direct learning ${ }^{[9,11,20]}$. The discussion enhances the student's ability to use theoretical information in practice ${ }^{[21]}$. Students from these focus groups could verbalize a better understand of the content within a context of the modeled nursing care. 


\section{Discussion}

The Institute of Medicine (IOM) report; the future of nursing: leading change, advancing health ${ }^{[22]}$ ) identifies the need to reform nursing education through the development of evidence-based, creative teaching-learning approaches which enhance the student nurse's clinical reasoning in patient care situations. Therefore, establishing contemporary teaching pedagogies is a priority and necessary to meet the needs of the complex health care environment in which future nurses will be practicing ${ }^{[23]}$. Overall, the students agree that the video exemplars with the debriefing component have a positive impact on learning. Faculty made videos impacted the perception of theory taught in the classroom through creation of a model to visualize. The debriefing component served to reinforce and correct any misconceptions. The themes of reinforced learning, visual learning value, and time to debrief are all relevant to the goal of assisting nursing students to develop the knowledge, skills, and attitudes necessary to provide evidenced based, high quality, and safe, patient centered care.

\section{Recommendations for future research}

There remains a growing need for strategies based on evidence to establish best practices in nursing education. According to SLT, modeling is a strategy that has a broad application to promote self-efficacy, cognitive knowledge development ${ }^{[1]}$, and thought processes ${ }^{[24]}$. Video based films with a debriefing component can be used to teach a wide range of cognitive, affective, and psychomotor skills essential to practice. Therefore, future research should continue in the area of modeling. Visual modeling of essential scenarios which exemplify critical nursing care accompanied by faculty debriefing to explain the thought processes behind clinical judgments, may be an effective approach for multiple behaviors.

Recently, Gates, Parr, and Hughen ${ }^{[25]}$ used examination scores as a measure of the effect of high fidelity simulation on knowledge acquisition. They found significantly higher scores in those students who participated in the simulation. Could visual modeling of vital information, skills, and attitudes also improve knowledge acquisition while promoting clinical judgment development? If so, audio-visual recordings could have broad application and provide a generalizable format to many schools of nursing. National initiatives to benchmark further development of recordings that model crucial concepts to the nursing profession are needed.

\section{References}

[1] Bandura, A. Origins of behavior. In A. Bandura (Ed.), Social Learning Theory (pp. 16-55). Englewood Cliffs, NJ: Prentice-Hall; 1977.

[2] Bandura, A. Efficacy of personal and collective efficacy in changing societies. In A. Bandura (Ed.), Self-Efficacy: The Exercise of Control (pp. 1-45). New York: W.H. Freeman \& Company; 1997.

[3] Alexander, L. Social learning theory and distance education: Compatible or incompatible constructs? Perspective on Physician Assistant Education. 2001; 12: 267-269.

[4] Price, V., Archibold, J. Development and application of social learning theory. British Journal of Nursing. 1995; 4: $1263-1268$. PMid:8574105

[5] Zimmerman, B. Self-efficacy and educational development. In: Bandura A. (Eds.). Self-efficacy: the exercise of control. New York: W.H. Freeman \& Company; 1997; 202-227.

[6] Bandura, A. Analysis of modeling processes. In A. Bandura (Rev. ed.), Psychological Modeling Conflicting Theories (pp. 1-62). New Brunswick: Transaction Publishers; 2007.

[7] Bahn, D. Social learning theory: Its application in the context of nurse education. Nurse Education Today. 2001; $21: 110-117$. PMid:11170797

[8] Perry, B. Role modeling excellence in clinical nursing practice. Nurse Education in Practice. 2009; 9, 36-44. PMid:18590978 http://dx.doi.org/10.1016/j.nepr.2008.05.001

[9] Lasater, K. High-fidelity simulation and the development of clinical judgment: Student experiences. Journal of Nursing Education, (2007a); 46(6): 269-276. PMid:17580739

[10] Lusk, J., Fater, K. Postsimulation debriefing to maximize clinical judgment development. Nurse Educator, 2013; 38(1): 16-19. PMid:23222625 http://dx.doi.org/10.1097/NNE.0b013e318276df8b 
[11] Tanner, C. A. Thinking like a nurse: A research-based model of clinical judgment in nursing. Journal of Nursing Education. 2006; 45: 204-211. PMid:16780008

[12] Bambini, D., Washburn, J., Perkins, R. Outcomes of simulation for novice nursing students: Communication, confidence, and clinical judgment. Nursing Education Research. 2009; 30: 79-82.

[13] Dreifuerst, K. The essentials of debriefing in simulation learning: A concept analysis. Nursing Education Perspectives. 2009; 30(2): 109-114. PMid:19476076

[14] Jeffries, P. Designing, implementing, and evaluating simulations used in teaching strategies in nursing. Nursing Education Perspectives. 2005; 26(2): 96-102. PMid:15921126

[15] Jeffries, P. Rogers, K. Theoretical framework for simulation design. In P. Jefferies (Ed.), Simulation in Nursing Education: From conceptualization to evaluation. New York, NY: NLN. 2007: 21-33.

[16] Arafeh, J., Hansen, S., Nichols, A. Debriefing in simulated-based learning: facilitating a reflective discussion. [corrected] [published erratum appears in J PERINAT NEONAT NURS 2011 Jul/Sep; 25(3)268]. Journal of Perinatal \& Neonatal Nursing. 2010; 24(4): 302-311. PMid:21045608 http://dx.doi.org/10.1097/JPN.0b013e3181f6b5ec

[17] Guhde, J. Clinical decision-making: using online exercises and patient simulation to improve students' clinical decision-making. Nursing Education Perspectives. 2010; 31(6): 387-389. PMid:21280447

[18] Ridley, R. Assuring ethical treatment of students as research participants. Journal of Nursing Education. 2009 ; 48: 537-541. PMid:19645366 http://dx.doi.org/10.3928/01484834-20090610-08

[19] Polit, D., Beck, C. Nursing Research: generating and assessing evidence for nursing practice (8th ed.). Philadelphia, PA, USA: Lippincott, Williams \& Wilkins; 2008.

[20] Benner P, Sutphen M, Leonard V, Day, L. Educating Nurses: A Radical Call for Transformation. San Francisco, CA: Jossey-Bass; 2010.

[21] Childs, J., Sepples, S. Chambers, K. Designing simulations for nursing education. In Jeffries, P. (Eds.), Simulations in Nursing Education from Conceptualization to Evaluation. New York, NY: NLN; 2007: 35-40.

[22] Institute of Medicine. The future of nursing: leading change, advancing health. Available from: http://www.iom.edu/Reports/2010/The-Future-of-Nursing-Leading-Change-Advancing-Health.aspx.

[23] Horsfall, J., Cleary, M. Hunt, G. Developing a pedagogy for nursing teaching-learning. Nurse Education Today. 2011; 32: 930-933. PMid:22100421 http://dx.doi.org/10.1016/j.nedt.2011.10.022

[24] Anderson, J. M., Aylor, M. E., Leonard, D. T. Instructional design dogma: Creating planned learning experiences in simulation. Journal of Critical Care. 2008; 23: 595-602. PMid:19056028 http://dx.doi.org/10.1016/j.jcrc.2008.03.003

[25] Gates, M. G., Parr, M. B., Hughen, J. E. Enhancing nursing knowledge using high fidelity simulation. Journal of Nursing Education. 2012; 51: 9-15. PMid:22085206 http://dx.doi.org/10.3928/01484834-20111116-01 